\title{
(息)
}

Citation:

Dobson, T and Rose, A (2019) The use of technology to enable school governors to participate remotely in meetings: A solution to skilled governor shortages in schools? Management in Education. ISSN 0892-0206 DOI: https://doi.org/10.1177/0892020619840075

Link to Leeds Beckett Repository record:

https://eprints.leedsbeckett.ac.uk/id/eprint/5771/

Document Version:

Article (Accepted Version)

The aim of the Leeds Beckett Repository is to provide open access to our research, as required by funder policies and permitted by publishers and copyright law.

The Leeds Beckett repository holds a wide range of publications, each of which has been checked for copyright and the relevant embargo period has been applied by the Research Services team.

We operate on a standard take-down policy. If you are the author or publisher of an output and you would like it removed from the repository, please contact us and we will investigate on a case-by-case basis.

Each thesis in the repository has been cleared where necessary by the author for third party copyright. If you would like a thesis to be removed from the repository or believe there is an issue with copyright, please contact us on openaccess@leedsbeckett.ac.uk and we will investigate on a case-by-case basis. 


\section{The use of technology to enable school governors to participate remotely in meetings: a}

\section{solution to skilled governor shortages in schools?}

\section{Dobson, T.; Rose, A.}

\section{Introduction}

England's National Governance Association's (NGA) 2017 survey of over 5000 school governors emphasises a crisis in recruitment with respondents indicating difficulties in recruitment of Governing Body (GB) members increasing from 50\% in 2015 to 53\% in 2016 and $56 \%$ in 2017 . $62 \%$ of schools have at least one governor vacancy and almost a third of schools (31\%) now have two or more governor vacancies (NGA, 2017). In a speech at the NGA's 2018 annual conference, the Education Secretary placed the recruitment of school governors firmly on the government's agenda, emphasising the role that the private sector can play (DfE, 2018).

Here we draw upon our Higher Education Institution's 18-month independent evaluation (Author 1 et al., 2018) of Lloyds Banking Group's (LBG) StandingOut (SO) Programme to look at one potential solution to skilled school governor recruitment - the use of technology to enable school governors to participate remotely in GB meetings. The SO programme facilitates LBG's employees to become independent, external, business-based governors (IEBs) and here we compare the experiences and contributions of the IEBs who attended meetings remotely with those who attended in person. In so doing, we identify the ways in which IT infrastructure, training and support needs to be improved in order to embrace the potential of using technology to enable remote participation in GB meetings as a response to governor shortages.

\section{Changes in school governance}


Changes in school governance reveal different trends in different countries. Whilst Lin and Wu (2013) and Viseu and Carvalho (2018) report on decentralised school governance in Japan and Portugal leading to school GBs requiring governors with business skills, in the differing political contexts of South Africa (Dukba and Isholaakindele, 2017) and Canada (Seel and Gibbons, 2012) there is a greater emphasis on community engagement and in Georgia (Gordgodze, 2016) there is a move towards recentralisation and government control. In England changes to school governance policy are linked to academisation (DfE, 2016), with schools requiring a GB's with the professional skills to secure performance evaluation to improve public service delivery (Wilkins, 2015: p.182). To satisfy Ofsted (the quality assurance body for schools in England), GBs require individuals who have, e.g., knowledge of the legal sector and running a business - skill-sets associated with the private sector. Running a school is now akin to 'running a business' (Wilkins, 2015: p.188). 75\% of all failing secondary schools are in the North and the Midlands of England (Ofsted, 2015) those pupils from the North from lower socio-economic backgrounds are down an average grade score of $6.5 \%$ on their London peers (Perraudin, 2018). Within this context, the government launched its 'Opportunity Areas' initiative (Gov.UK, 2016), the purpose of which is to focus local and national resources on the common aim of increasing social mobility through education (Gov.Uk, 2017). Twelve 'Opportunity Areas' include Bradford and the North Yorkshire Coast - areas covered by the LBG's SO programme. It is widely accepted that the challenges facing school GBs are greater in areas of socio-economic disadvantage (James et al., 2013: 415) such as Yorkshire and Humberside.

\section{Remote governance}

Identifying 'cold spots' within the Yorkshire and Humberside region where rural or coastal schools were finding it difficult to recruit governors, LBG piloted IEB governors who would 
dial into meetings rather than attend in person. LBG provided schools with WebEx (technology providing sound and vision) to facilitate this. At the start of our evaluation, ten remotely operating IEBs were recruited - five took part in our evaluation.

Whilst there is no literature relating directly to remote governance of schools, the concept of e-governing, where achieving governor responsibilities through 'the use of IT' (Mundy and Musa, 2010: p.147), has potential. Here we define e-governing as using IT to allow governors to attend meetings remotely rather than using IT to facilitate paperless meetings which governors attend in person.

\section{School governance as a diverse landscape of practice}

A GB, however, represents a specific cultural context, which differs from country to country, and which requires specific attention in relation to the application of e-Government practices. In England, the focus upon governors with business skills led Young (2017) to analyse GB interactions as the interaction of three knowledge types - 'managerial', 'educational', and 'lay' - in the process of deliberative democracy. Whilst Young (2017) argues that 'lay' knowledge is marginalised by 'managerial' knowledge, our paper on the SO Programme (Author 1 et al, 2018a), looks at the ways in which IEB governors were more tentative in their participation. Using Wenger-Trayner and Wenger-Trayner's (2014) metaphor of a 'landscape of practice', we see GB's in England as 'diverse' in the ways in which Young's three knowledge types interact. It is this diversity which requires GB participants to 'cross boundaries' and achieve 'hybridisation' of practice (Clark et al, 2017) in order to become effective members. In relation to IEBs attending meetings remotely, here we highlight the barriers to achieving 'hybridisation'.

\section{Evaluation design}


The evaluation ran over four school terms (autumn 2016 to autumn 2017) and gathered qualitative and quantitative data through interviews, school case studies, surveys and workshops. 10930 minute interviews were carried out and fully transcribed with a range of stakeholders. This included four interviews with eighteen IEBs over a 12 month period, five of whom were attending GB meetings remotely. In relation to these IEBs, interviews were also undertaken with: 2 Chairs of Governors (Chair); 2 Headteachers; 1 Chief Executive Officer (CEO).

This paper is a small study of five IEBs during the first 12 months of their GB tenures. As outlined in Table 1, IEB1 and IEB3 were appointed by the same primary school; the other three IEBs were appointed by schools for pupils with special educational needs. The distance between a participant's home and the school is recorded, as is the approximate location of the school. In relation to the school stakeholder interviews, roles held are listed. Finally, the seniority of the roles held at LBG are also stated as these did have some bearing upon the extent to which participants were able to participate as IEBs.

[Table 1 near here]

\section{Data analysis}

The evaluation team thematically analysed the interview transcripts in relation to LBG's project aims (Author 1 et al, 2018b). This allowed for the generation of case studies where comparisons were made between IEBs attending meetings in person and IEBs attending meetings remotely. Further to this, Young's (2017) heuristic of knowledge as 'managerial', 'educational' and 'lay' was used to think about how the IEBs themselves and key stakeholders perceived the participation of IEBs.

In relation to LBG's aims, we begin by discussing the school stakeholder interviews and their motivations for appointing an IEB who would attend meetings remotely. We then discuss the ways in which these IEBs used their 'managerial' knowledge to make an impact 
upon their GBs, before exploring why this impact was valued more by schools than the IEBs themselves. In order to explain this discrepancy, we identify the barriers to acquiring 'educational' and 'lay' knowledge experienced by IEBs and finish by looking at the ways in which technology, training and support could be improved to facilitate effective participation and 'hybridisation' of practice.

\section{Motivations for recruiting an IEB attending meetings remotely}

Key stakeholders at all four schools wanted to appoint an IEB who would attend meetings remotely because they were struggling to fill governor vacancies. This was because the schools were located in rural and not particularly affluent areas with few skilled professionals wanting to take on a governor role. IEB1 and IEB3's Chair commented: 'The school is quite out on its own really so being able to appeal to skilled professionals can be quite difficult.... So it's broadening the area we can pull from really.'

For IEB2, IEB4 and IEB5's schools, undertaking GB skills audits had revealed the need for skilled governors with 'managerial' knowledge who could complement the skills of the existing GB. IEB4's Chair commented, 'a very beneficial way forward is to be able to have someone on our GB that can add that area of expertise and IEBs operating remotely has worked.'

\section{The impact of 'managerial' knowledge}

All four schools valued the contributions and impact made by these IEBs in a way that is comparable with those made by the other IEBs. The main contribution these IEBs made related to their 'managerial' knowledge as they brought a different, objective viewpoint to GB meetings, asking relevant and challenging questions. Accordingly, IEBs were found to be analytical, especially in relation to the data and were able to provide a different slant on key issues due to their skill-sets and professional background. IEB1 and IEB3's Chair commented: 'We found ourselves with two very highly skilled governors who are able to ask quite pertinent 
and quite challenging questions.' Compared with other GB members, the Chair felt the IEBs were 'able to just look at the data, look at the reports that are being presented, they're able to objectively look at all of the data and really drill down on the data.' According to IEB2's Chair, her skills meant she 'raised the bar' at GB meetings through the business perspective she brought to the discussions.

In line with this, all schools felt that their IEBs had raised the confidence of their GB. A specific example came from IEB2's Chair, who spoke about how he was able to ask pertinent questions from an outsider's perspective, which ultimately had a 'massive impact' on the school's decision concerning which academy they should go with.

Whilst all IEBs were felt to have had some impact in strengthening their school's business practices, IEB5 was most instrumental in improving the finances of her school by working with the new Chair: 'a lot of our conversations were around the financial aspects of the school... IEB5 was able to act as a mentor to me when I was starting to move things forward with the Headteacher.'

Overall, due to the impact of 'managerial' knowledge, all schools felt their IEBs had lived up to expectation and would recommend them to other schools. IEB2's Headteacher was particularly effusive: 'I think they're brilliant really because I would not have been able to get other governors, because people don't want to attend.' The fact that IEBs did not have to attend GB meetings in person meant they were much more likely to attend virtually and make the kinds of contributions and impacts outlined above. This likelihood of attending meetings was further re-enforced by LBG allowing its volunteer governors to attend meetings during working hours.

Whilst schools were positive about the contributions and impact IEBs made, the IEBs themselves were far more reticent to claim they had made a difference to their schools GB. All five IEBs were hesitant to say whether they had been able to increase the confidence, 
knowledge and skills of their GB, although they did feel they brought a 'different perspective' to meetings. In relation to strengthening the school's business practices, most of the IEBs felt that it was 'too early to say' whether they had made an impact.

\section{Barriers to acquiring 'educational' knowledge}

The discrepancy between the perspectives of the schools and the IEBs in relation to impact can perhaps be attributed to the barriers experienced by the IEBs in engaging with their GBs and schools and acquiring the necessary 'educational' knowledge. These barriers were apparent at each stage of the settling-in process, from initial training and induction to throughout the academic year. In relation to training, whilst all IEBs had access to the same range of online resources and training programmes, in some instances there was an expectation placed by schools upon these IEBs to attend face-to-face induction training. For IEB1, IEB3 and IEB5, the travel time was impractical with IEB1 commenting: 'because of the distance that's involved it's physically impossible to attend those.' Furthermore, there was a perception amongst the IEBs that attending training in person was beyond the remit of what they had signed up to in the first place.

Training aside, all 5 IEBs and their schools experienced different degrees of problems with the technology designed to engage them in GB meetings. These were quickly resolved in the case of IEB4 but the other four IEBs experienced ongoing technical problems that, in some cases, were never resolved. For IEB2, the visuals for WebEx never worked and they resorted to using telephones without visuals instead. For IEB1 and IEB3, the WebEx visuals were often intermittent and this compromised how they felt about their participation in GB meetings. IEB5 experienced the worst problems with the school never being able to get any of the technology to work and with IEB5 having to correspond directly and only with the Chair outside of meetings. As IEB5 identified, this was in part down to the culture of the GB: 'they just don't operate in that way, they work on a face-to-face basis - that you're in the room for the 
meetings.' More than this, the school's physical environment was seen by the Chair as not accommodating the remote governance concept: 'it's a very old school. The technology is about 30 years behind the times and we just really had problems in getting an audio contact with IEB5 during meetings'.

Two of the IEBs also faced technical barriers relating to the customer-facing nature of their professional role within LBG. For IEB1 this was resolved through LBG providing him with a laptop; for IEB3, his role in a Call Centre meant that he did not have the necessary hardware to attend meetings during work-time due to 'data protection' constraints within the company. IEB3's difficulties were further compounded by his Call Centre role at LBG meaning that he did not have the flexibility to attend meetings which had been afforded to more senior LBG employees.

These barriers in relation to induction, training and virtual attendance at GB meetings meant that these IEBs were less likely than other IEBs to acquire 'educational' knowledge in order to take on specific roles on sub-committees within their schools. Indeed, whilst other IEBs had at least one specific role in addition to being on the main GB, this was the case for only two of the IEBs attending meetings remotely. The barriers to engagement experienced by the IEBs meant, as a whole, the IEBs attending meetings remotely did not settle into their roles as quickly or effectively as the other IEBs. IEB1 and IEB3 still felt detached from their role one year in, largely due to the distance from the school and some continuing technological issues.

The barriers to engagement felt by IEB5 became so great that by the end of her first year in post she felt that she had no other option but to resign. However, according to the CEO, IEB5's Multi Academy Trust (MAT) made two similar appointments, who were not part of this evaluation, but who took to their roles more effectively than IEB5 as they lived near enough their schools to make a visit and attend GB meetings in person. Accordingly, one of these IEBs 
was appointed as an advisor to the MAT's Audit and Finance committee; the other has physically attended most meetings and is now Chair of Governors at her allocated school. The CEO explained:

She was able to physically attend meetings more. She came in through the remote governance programme but she's able to be more than a remote governor but if we'd not engaged in the programme we would not have ended up with her being a physical presence around our governing body table and now Chair.

\section{The importance of relationships and 'lay' knowledge}

For IEB1 and IEB3's Chair, a problem with the remote governance model was around forging relationships with other GB members. Given that GBs are together perhaps once or twice a term, this was even a challenge for those IEBs who did attend meetings, but when IEBs attend virtually with technological issues, barriers to building relationships become exacerbated. IEB1 and IEB3's Chair commented that this was a key issue which required further thought: Everybody's valued but I think one of the difficulties of having IEBs really is it's quite difficult to get to know them because obviously you don't see them before the meetings and after. So I think that one of the areas that [needs] addressing is how you build up the social side of things, which is important.

Indeed, IEB1 did ultimately felt so compelled to try to build a relationship with his GB that he undertook a 200-mile round trip in order to do so. He commented:

I understand the actual principles behind the project in the first place to try and reach these remote locations, but having that face-to-face contact, you know, the hand shake and the sitting down with governors, I think helps cement the relationship that much stronger. 
In line with this, where IEBs did settle into their roles more quickly, a key variable was the relative proximity between their homes and schools. For IEB2 (50 minutes travel time) and IEB4 (60 mile round trip), the distance was not prohibitive of them attending occasional GB meetings in person and undertaking school visits and this meant that they both felt part of their respective GBs and acquired the 'lay' knowledge relating to the specific context of their schools, its staff and pupils . As IEB2 commented, attending meetings in person at the start of their appointment helped her develop a working relationship with the rest of the GB and enabled her to then participate more fully in meetings by dialling in:

I'd been to a few of the meetings so I'd met them all face-to-face and they were a really good group of people. So being on the phone worked really well because I never felt like they'd forgotten that I was there and they kept me included as and when if anything was happening.

\section{Conclusions}

Although a small sample, the impact of the five IEBs operating remotely on their respective schools from the perspective of school stakeholders indicates the potential such a model of skilled governance has as a solution to governor recruitment shortages. However, whilst school stakeholders and IEBs themselves recognised the impact of the IEBs' 'managerial' knowledge upon the GB, the lack of face-to-face contact also meant these IEBs had the potential to feel like outsiders in relation to working with their respective GBs and understanding their schools. As illustrated, this feeling of being an outsider was often exacerbated by issues with technology as well as outdated GB practices and frequently IEBs were left feeling that they were not making much of a contribution. For IEB5, this feeling became so great that she felt she had no choice other than to resign.

With this affective dimension of governance in mind, we recommended to LBG that, given the current technological problems in schools, IEBs attending meetings remotely should, 
from a geographical perspective, be able to visit their schools in order to develop 'lay' knowledge and attend meetings to acquire 'educational' when necessary. This would in turn facilitate the 'hybridisation' (Clark et al, 2017) necessary to participate in a 'diverse landscape of practice' (Wenger-Trayner and Wenger-Trayner, 2014).

More broadly, the evaluation of the participation of these IEBs highlights the need for further context-specific research into the ways in which remotely based governors can contribute to school governance. This should include consideration of how technology could reshape the composition of a GB in terms of diversity, skills and local stakeholders.

Furthermore, where school governance does include IEBs attending meeting remotely, consideration should be given to: the technical support required by the individual school; how aspects of school life could be portrayed to governors in order to develop their 'lay' knowledge; how training and induction for governors can be improved to help them acquire both 'educational' and 'lay' knowledge.

\section{References}

Author 1, Author 2, Parton, G. and Hart, M. 2018a. Boundary Crossing in School Governing Bodies: Perspectives from the Business Community. Educational Management Administration \& Leadership. Accessed $13 \quad$ December 2019 https://journals.sagepub.com/doi/full/10.1177/1741143218814005.

Author 1, Author 2, Parton, G. and Hart, M. 2018b. Evaluation of the LBG Flagship School Governance StandingOut Programme - Final Report January 2018. Accessed 20 May 2018. https://www.leedsbeckett.ac.uk/-/media/files/school-of-education/cse-final-report.pdf?la=en.

Clark, J., Laing, K., Leat, D., Lofthouse, R., Thomas, U., Tiplady, L. and Woolner, P. 2017. Transformation in interdisciplinary research methodology: the importance of shared experiences in landscapes of practice. International Journal of Research and Method in Education 40: 243-256.

Clifton J., Round A. and Raikes L. 2016. Northern Schools: Putting Education at the Heart of the Northern Powerhouse. Manchester: IPPR North. Accessed 20 May 2018. http://www.ippr.org/files/publications/pdf/northern-schools_May2016.pdf?noredirect=1. 
DfE. 2018. Damian Hinds speech at NGA Conference. Accessed 11 June 2018.

https://www.gov.uk/government/speeches/damian-hinds-speech-at-national-governanceassociation-conference.

DfE. 2016. Education, Excellence and Everywhere. London: HMO. Accessed 20 May 2018. https://www.gov.uk/government/uploads/system/uploads/attachment_data/file/508447/Educa tional_Excellence_Everywhere.pdf.

Duku, N \& Salami, Isholaakindele. (2017). The relevance of the school governance body to the effective decolonisation of education in South Africa. Perspectives in Education, 112-125. Gorgodzel, S. (2016) Rise and Fall of Decentralized School Governance - Decision-Making Practices in Georgia. International Education Studies 9.11: 25-39.

Gov.UK. 2017. Education secretary announced 6 new opportunity areas. Accessed 14 May 2018. $\quad$ https://www.gov.uk/government/news/education-secretary-announces-6-newopportunity-areas.

Gov.UK. 2016. Social mobility package unveiled by Education Secretary. Accessed 20 May 2018. https://www.gov.uk/government/news/social-mobility-package-unveiled-by-educationsecretary.

James, C., Brammer, S., Connolly, M., Spicer, D.E., James, J. and Jones, J. 2013. The challenges facing school GBs in England: A 'perfect storm'? Management in Education 27(3): 84-90.Lin, Y., and Wu, C. 2013. Analyses and Changing Models of School Governance in Japan: School Council Cases. Journal of Research in Education Sciences 58.4: 103-131.

Mundy, D., and Musa, M. 2010. Towards a Framework for eGovernment Development in Nigeria. Electronic Journal of e-Government 8.2: 148-161.

Mustafa, K. (2018) Mobile governance in Cloud. iJES 6.2: 46-60.

Ofsted. 2015. The annual report of Her Majesty's Chief Inspector of Education, Children's Services and Skills 2014/15. Accessed 8 May 2018. https://www.gov.uk/government/publications/ofstedannual-report201415-education-and-

$\underline{\text { skills }}$

Perraudin, F. 2018. Disadvantaged pupils achieve lower grades in the North than in London. $\begin{array}{lllll}\text { The } & \text { Guardian. } & \text { Accessed } & \text { May } & \end{array}$ https://www.theguardian.com/education/2018/feb/01/disadvantaged-pupils-achieve-lowergrades-in-north-than-in-london

Seel, K., and Gibbons, J. (2012) Governance in Transformation: Alberta School Board Chairs' Perspectives. ANSERJ 3.1: 26-41. 
Wenger-Trayner, E. and Wenger-Trayner, B. 2014. Learning in a Landscape of Practice. In: Wenger-Trayner, E., Fenton O’Creevy, M., Hutchinson, S., Kubiak, C. and Wenger-Trayner, B. (eds) Learning in Landscapes of Practice: Boundaries, Identities and Knowledgeability in Practice-Based Learning. Oxon: Routledge, 12-19.

Viseu, S., and Carvalho, L. M. 2018. Changes in school governance and the reshaping of head teachers' roles and identities in Portugal. Education policies and the restructuring of the educational profession. Global and comparative perspectives. Singapore: Springer Verlag: 5770.

Wilkins, A. 2015. Professionalizing school governance: the disciplinary effects of school autonomy and inspection on the changing role of school governors. Journal of Education Policy 30.2: 182-200.

Young, H. 2017. Knowledge, Experts and Accountability in School GBs. Educational Management Administration \& Leadership 45.1: 40-56. 